\title{
Obstacles to prompt and effective malaria treatment lead to low community-coverage in two rural districts of Tanzania Manuel W Hetzel ${ }^{* 1,2,4}$, Brigit Obrist ${ }^{1}$, Christian Lengeler ${ }^{1}$, June J Msechu ${ }^{2}$, Rose Nathan ${ }^{2}$, Angel Dillip², Ahmed M Makemba², Christopher Mshana ${ }^{2}$, Alexander Schulze ${ }^{3}$ and Hassan Mshinda ${ }^{2}$
}

\begin{abstract}
Address: ${ }^{1}$ Dept. of Public Health and Epidemiology, Swiss Tropical Institute, P.O. Box, CH-4002 Basel, Switzerland, ${ }^{2}$ Ifakara Health Institute, P.O. Box 53, Ifakara, Tanzania, ${ }^{3}$ Novartis Foundation for Sustainable Development, WRO-1002.11.56, CH-4002 Basel, Switzerland and ${ }^{4}$ Papua New Guinea Institute of Medical Research, P.O. Box 60, Goroka, EHP 441, Papua New Guinea
\end{abstract}

Email: Manuel W Hetzel* - manuel.hetzel@unibas.ch; Brigit Obrist - brigit.obrist@unibas.ch; Christian Lengeler - christian.lengeler@unibas.ch; June J Msechu - joliejj@yahoo.com; Rose Nathan - rnathan@ihi.or.tz; Angel Dillip - adillip@ihi.or.tz;

Ahmed M Makemba - amakemba@ihi.or.tz; Christopher Mshana - cmshana@ihi.or.tz; Alexander Schulze - alexander.schulze@novartis.com; Hassan Mshinda - hmshinda@ihi.or.tz

* Corresponding author

Published: 16 September 2008

BMC Public Health 2008, 8:317 doi:10.1 I86/147|-2458-8-317
Received: 3I August 2007

Accepted: 16 September 2008

This article is available from: http://www.biomedcentral.com/I47I-2458/8/3I7

(c) 2008 Hetzel et al; licensee BioMed Central Ltd.

This is an Open Access article distributed under the terms of the Creative Commons Attribution License (http://creativecommons.org/licenses/by/2.0), which permits unrestricted use, distribution, and reproduction in any medium, provided the original work is properly cited.

\begin{abstract}
Background: Malaria is still a leading child killer in sub-Saharan Africa. Yet, access to prompt and effective malaria treatment, a mainstay of any malaria control strategy, is sub-optimal in many settings. Little is known about obstacles to treatment and community-effectiveness of case-management strategies. This research quantified treatment seeking behaviour and access to treatment in a highly endemic rural Tanzanian community. The aim was to provide a better understanding of obstacles to treatment access in order to develop practical and costeffective interventions.

Methods: We conducted community-based treatment-seeking surveys including 226 recent fever episodes in 2004 and 2005. The local Demographic Surveillance System provided additional household information. A census of drug retailers and health facilities provided data on availability and location of treatment sources.

Results: After intensive health education, the biomedical concept of malaria has largely been adopted by the community. $87.5 \%$ (78.2-93.8) of the fever cases in children and $80.7 \%(68.1-90.0)$ in adults were treated with one of the recommended antimalarials (at the time SP, amodiaquine or quinine). However, only $22.5 \%$ (I3.9-33.2) of the children and $10.5 \%(4.0-21.5)$ of the adults received prompt and appropriate antimalarial treatment. Health facility attendance increased the odds of receiving an antimalarial $(O R=7.7)$ but did not have an influence on correct dosage. The exemption system for under-fives in public health facilities was not functioning and drug expenditures for children were as high in health facilities as with private retailers.

Conclusion: A clear preference for modern medicine was reflected in the frequent use of antimalarials. Yet, quality of case-management was far from satisfactory as was the functioning of the exemption mechanism for the main risk group. Private drug retailers played a central role by complementing existing formal health services in delivering antimalarial treatment. Health system factors like these need to be tackled urgently in order to translate the high efficacy of newly introduced artemisinin-based combination therapy (ACT) into equitable communityeffectiveness and health-impact.
\end{abstract}




\section{Background}

Malaria kills more than one million people annually, mostly children under five years of age in sub-Saharan Africa. As part of an integrated approach to malaria control, the World Health Organization promotes prompt access to effective treatment for all episodes of malaria [1]. However, it can be safely assumed that of the 2.4 billion people (2005) living in low-income countries [2], only few have access to high quality health-care, including appropriate malaria-treatment [3-5].

Increased attention to the issue of access to treatment is required in the light of rolling-out highly efficacious artemisinin-based combination therapy (ACT). Lack of access is a complex issue that can be better understood when seen in the context of poverty, vulnerability and livelihoods [6]. Which obstacles to treatment are relevant - and should be addressed by interventions - depends to a large extent on the local setting [3]. As there is no onesize-fits-all solution, several strategies have been proposed and tested to improve access to malaria treatment. These include scaling-up home-based management $[7,8]$, stronger involvement of the private sector $[9,10]$, improving case-management in health facilities [11] as well as integrated approaches [12]. In addition, it is now widely acknowledged that no malaria-control strategy can be successful and sustainable without an increased investment in the local health system through which the interventions are to be channelled [13-15].

In order to develop targeted and cost-effective interventions, it is essential to add to the knowledge of treatment rates an understanding of the major obstacles to treatment access in a particular setting. For Tanzania, the 2004-5 Demographic and Health Survey (DHS) reported 58.2\% antimalarial use in children under 5 years of age with a recent fever [16]. Yet, how many of these children received appropriate treatment, in a timely fashion and in the correct dose - or why others did not receive an antimalarial drug - is not elaborated upon in DHS surveys.

The studies presented here assessed the impact of local knowledge of malaria and treatment seeking practices on access to malaria treatment in a rural Tanzanian community. The research was carried out in the frame of a comprehensive intervention programme which aims to improve access to malaria treatment in rural Tanzania (ACCESS Programme) [17].

\section{Methods \\ Study setting}

Treatment seeking for fever episodes was studied in the districts of Kilombero and Ulanga, south-eastern Tanzania, in 2004 and 2005. The study area comprised the 25 villages of the local Demographic Surveillance System
(DSS) [18] with a population of 74,200 in 2004, as well as the town of Ifakara, the district capital of Kilombero (2001 population census: 45,726 [19]). The area is predominantly rural and malaria transmission is high and perennial [20,21]. In 2004, there were 14 health facilities (9 public, 5 private/mission) in the DSS area, as well as one private clinic and one district hospital in Ifakara. Malaria accounted for roughly half of all outpatient visits in these facilities. Government and private health facilities in Kilombero were running on a cost-sharing scheme. In Ulanga, no user fees were charged in government facilities and a Community Health Fund (CHF) offered a form of risk-protection for members of the fund. A detailed description of the study area can be found elsewhere [17]. At the time of the study, the recommended first-line treatment for uncomplicated malaria was SP, the second line treatment amodiaquine; quinine was recommended as third-line treatment and for cases of severe malaria [22].

\section{Treatment seeking surveys}

To investigate local understanding of malaria and treatment seeking behaviour for recent fever cases, a cross-sectional cultural-epidemiological community survey was conducted in the DSS area and Ifakara. We took a villagestratified random sample with the number of households sampled proportional to the total number of households in the village. A total of 318 households were drawn from the registered 16,220 households in the 25 DSS villages. Only households with at least one child under the age of five years were eligible.

Sampled households were visited by a DSS interviewer between May and August 2004, within the schedule of the routine DSS data collection. In all households in which a fever episode in the previous 14 days was reported, the patient or caretaker (if the patient was younger than 12 years) was interviewed. Patients who had not yet recovered were not included, as their options for treatmentseeking were not yet exhausted. They were instead advised to seek care from a health facility.

For Ifakara town no up-to-date household list was available as a sampling frame. The local administrative structure was used to establish a list of households and to perform a two-stage random sampling of 223 households. Every household in Ifakara was assumed to belong to a ten-cell (a group which was originally composed of ten households) and be represented by a ten-cell leader (balozi). Through visits to local government officials, a comprehensive list of all 329 ten-cell leaders in Ifakara was established. A random sample of 35 ten-cell leaders was then visited in order to establish a complete household list for their ten-cells. Six households per ten-cell were then randomly sampled. A household may only have been missed if it was not recorded by any ten-cell leader. We tried to 
avoid double-listing of households claimed by several ten-cell leaders by cross-checking the names of the household heads. Sampled households were visited by two trained interviewers in May 2004. The same inclusion and exclusion criteria as in the DSS villages applied.

Spatial data on household locations as well as socio-economic status calculations were obtained from the DSS database, which provided such information for $70 \%$ of all interviewed cases. In order to consider distance to the nearest point of care as a predictor for treatment access, we also used geo-spatial data of 16 health facilities and 498 drug selling shops (DSS and Ifakara), collected during a survey in May - June 2004 [23].

Additional information was derived from a longitudinal study on treatment seeking behaviour during the main farming season. This shamba cohort (in Swahili, shamba= farm) included a random sample of approx. 100 farming households from 10 randomly selected DSS villages which were followed-up during the main cultivation period between December 2004 and August 2005. Every month, interviews were done with recent fever cases, applying the same inclusion and exclusion criteria as in the cross-sectional community survey. A detailed description of this study can be found elsewhere [24].

As the sampling methodologies differed (cross-sectional vs. longitudinal; general population vs. only farming households), the two studies may not be equally representative of the general population. For the analysis of people's understanding of malaria it was assumed that there would be no difference between the two samples and both datasets were pooled for analysis. However, the treatment seeking and risk factor analysis for the shamba cohort study was done separately and presented elsewhere [24].

In both studies, field-workers used an Explanatory Model Interview Catalogue (EMIC) for data collection [25]. This semi-structured interview guide was developed on the basis of preceding focus-group discussions and further qualitative research on people's understanding and experience of malaria [26-28]. EMIC data comprised quantitative information and narratives of reported signs and symptoms ("patterns of distress"), perceived causes of the illness, and resulting treatment-seeking behaviour. Apart from the reported signs and symptoms, the data analysis took into consideration the name given to the illness by the respondent (illness label).

Oral informed consent was obtained from all study participants prior to the interviews. Ethical clearance for both studies was granted by the National Institute for Medical
Research of the United Republic of Tanzania (NIMR/HQ/ R.8a/Vol. IX/236, 16th September 2003).

\section{Statistical analysis}

Epi Info 6 was used for random sampling procedures. Data were double entered in Microsoft FoxPro and Microsoft Access (Microsoft Corp.), and checked for coding errors and consistency. Statistical analysis was done with Intercooled Stata 9 (College Station, Texas, USA). For spatial analyses, MapInfo Professional 7.0 (MapInfo Corp., Troy, New York, USA) and ArcView GIS 3.3 (ESRI, Redlands, CA, USA) were used.

For cultural-epidemiological data on patterns of distress (PD) and perceived causes (PC), answers were categorized and given values according to whether they were reported spontaneously (value of 2) or upon probing (value of 1). From these values, means were calculated as a measurement of the prominence of the respective features in the interviewee's accounts. Similar PD and PC were grouped for analysis and ranked according to their prominence in the interviewee's accounts. The Kruskal-Wallis test was used to test differences in the ranked outcomes between sub-groups of the sample. $\mathrm{Chi}^{2}$ and Fisher's exact tests were used to test associations.

Univariate and multivariate logistic models were fitted to assess the effect of several predictors on prompt and effective treatment, as defined below. Univariate analysis was conducted for all possible predictors on which data had been collected within the frame of the programme. For the multivariate models, a stepwise backward estimation was performed with a $\mathrm{P}>0.2$ significance level for removal from the model. The likelihood ratio test was used for significance testing. Both analyses considered village vs. town as predictor, but not individual villages. The sampling strategy of households as described above was unlikely to have resulted in over-sampling of any of the villages. We therefore performed aggregate level analyses which should give unbiased estimates without any village weighting. In addition, the number of individuals from each village was very small and hence estimating or allowing for within-village correlation factors in the regression analysis would be meaningless.

\section{Results \\ Study sample}

In the cross-sectional community survey, 154 recent fever cases were identified (approximately 28\% of all sampled households). In order to establish a clear distinction between cases in children and cases in adults, we only considered the cases aged under five years ( 80 children) and over 12 years (57 adults) for our analysis. The shamba survey added another 29 children under five years and 28 
adults over 12 years to the sample. Basic characteristics of the sample are summarized in Table 1.

\section{Local understanding of febrile illness}

The analysis of patterns of distress and perceived causes considered all children under the age of five years and adults over 12 years (194 in total).

Based on the illness labels given by the interviewees, fever cases were classified into three illness categories that roughly correspond with biomedical malaria. Of the child cases, 68 (62\%) were labelled malaria, 24 (22\%) homa (literally: fever), and $8(7 \%)$ degedege (convulsions, usually known only as an illness of young children). Of the adult cases, 54 (64\%) were labelled malaria, 26 (31\%) homa, and $2(2 \%)$ degedege. This classification is popular in the community as has been described in detail in earlier qualitative studies from Tanzania [26,28,29]. Homa and malaria cases were more relevant for this analysis than the relatively rare degedege-labelled cases. We included the degedege cases reported in children, but excluded the two adult cases. A detailed list of PD and PC variables with corresponding prominence values is available as an online supplement to this paper [see Additional file 1].
Patterns of distress (PD)

In children, fever symptoms and loss of strength were most prominently mentioned. "Having no strength" was significantly more prominent in the malaria compared to the homa category $(\mathrm{P}=0.023)$, as was vomiting $(\mathrm{P}=$ 0.033). Vomiting was generally more prominent than diarrhoea. Signs and symptoms related to convulsions (such as twitching, stiff body, "eyes turn white", kicking of arm or leg, froth in the mouth, mouth twisted sideways, as well as delirium, falling down, and being easily startled or frightened) were most prominent in the degedege category. Twitching was significantly more prominent in the degedege than the malaria $(\mathrm{P}=0.029)$ and the homa categories $(\mathrm{P}=0.022) .68(62.4 \%)$ cases showed at least one of the aforementioned signs of convulsions. Of these, 44 (61.1\%) were labelled malaria, 15 (20.8\%) homa, and 7 $(9.7 \%)$ degedege, showing clearly that many caretakers make a link between convulsions and malaria. Respiratory symptoms were not very prominent [see Additional file 2 - Figure A1].

In adults, there was no clear difference in reported PD between homa and malaria cases. Symptoms related to body strength or pain (particularly headache) were at least as prominent as fever. Nausea and vomiting were more prominent than diarrhoea. Difficult breathing or cough

Table I: Sample characteristics

\begin{tabular}{|c|c|c|c|c|}
\hline \multirow[t]{2}{*}{ Characteristics } & \multicolumn{2}{|c|}{2004 community survey $(N=137)$} & \multicolumn{2}{|c|}{2005 shamba survey $(\mathrm{N}=57)$} \\
\hline & $\mathbf{n}$ & Percentage & $\mathbf{n}$ & Percentage \\
\hline \multicolumn{5}{|l|}{ Age group } \\
\hline under 5 years & 80 & 58.4 & 29 & 50.9 \\
\hline over 12 years & 57 & 41.6 & 28 & 49.1 \\
\hline \multicolumn{5}{|l|}{ Sex } \\
\hline Female & 76 & 55.5 & 25 & 43.9 \\
\hline Male & 61 & 44.5 & 32 & 56.1 \\
\hline \multicolumn{5}{|l|}{ Residence } \\
\hline Ulanga DSS villages & 53 & 38.7 & 31 & 54.4 \\
\hline Kilombero DSS villages & 44 & 32.1 & 26 & 45.6 \\
\hline Ifakara & 40 & 29.2 & NA & NA \\
\hline \multicolumn{5}{|c|}{ Religion (of caretaker if patient $<12$ years) } \\
\hline Muslim & 51 & 37.2 & 21 & 36.8 \\
\hline Christian & 84 & 61.3 & 36 & 63.2 \\
\hline \multicolumn{5}{|c|}{ Years of formal education (of caretaker if patient $<12$ years) } \\
\hline Mean (years) & \multicolumn{2}{|c|}{$5.4(95 \% \mathrm{Cl} 4.83,5.89)$} & \multicolumn{2}{|c|}{$6.5(95 \% \mathrm{Cl} 6.01,6.97)$} \\
\hline Median (years) & \multicolumn{2}{|c|}{7 (51.1\% of sample) } & \multicolumn{2}{|c|}{7 (77.2\% of sample) } \\
\hline \multicolumn{5}{|c|}{ Household income regular and dependable } \\
\hline Yes & 68 & 49.6 & 33 & 57.9 \\
\hline Possibly & 18 & 13.1 & 3 & 5.3 \\
\hline Uncertain & 13 & 9.5 & 7 & 12.3 \\
\hline No & 38 & 27.7 & 14 & 24.6 \\
\hline
\end{tabular}


were less prominent in adults than in children. Convulsion-symptoms, such as twitching, were not probed - but also not mentioned spontaneously [see Additional file 2 Figure A1].

\section{Perceived causes (PC)}

Fever cases in children were most commonly attributed to mosquito bites. A "bird or insect called degedege", previously reported to be seen as a cause of degedege [29] was not significantly associated with degedege nor with signs of convulsions. The physical constitution of a child was rather seen as a cause of homa than malaria $(\mathrm{P}=0.023)$. Homa rather than malaria was often seen as a "stage of child growth" $(\mathrm{P}=0.033)$. Cold weather as a cause was most prominent in the homa, and least prominent in the malaria category $(\mathrm{P}=0.044)$. Heat as well as cold weather, was prominently mentioned as a cause of degedege. Supernatural causes (God, spirits, sorcery, etc.) were rarely mentioned. However, of all these, God was mentioned prominently in the malaria category, just after mosquito bites [see Additional file 2 - Figure A2].

Also in adults, mosquito bites were mentioned most prominently. Physical constitution was rather seen as a cause of homa than malaria. Sanitation or a dirty environment were more prominent in the malaria category $(\mathrm{P}=$ $0.040)$, while climate-related causes were more prominent in the homa category $(\mathrm{P}=0.057)$. God was the most prominently mentioned supernatural cause [see Additional file 2 - Figure A2]. A more detailed description of local illness concepts can be accessed elsewhere [30].

\section{Help seeking for fever episodes}

The analysis of help seeking for a recent febrile illness episode considered only the 2004 cross-sectional community survey data.

\section{Immediate help-seeking action}

Once a fever episode was recognized, most children and adults took an antipyretic drug, about $70 \%$ of them on the day of illness onset or the day after. Antimalarial drugs were less popular as first help seeking action: only $35.0 \%$ (24.7-46.5) of all children and 42.1\% (29.1-56.0) of all adults took an antimalarial on the same or the next day. $62.5 \%$ of all caretakers brought their sick child to a health facility as first action, $45.0 \%(33.9-56.5)$ of them within two days. Significantly fewer adults attended a health facility as first action (33.3\%) and only $21.1 \%$ (11.433.9) went there within two days. Cooling one's body through sponging or a cold bath was done by over $30 \%$ of all children and adults. Traditional medicine or divination, however, was not common (Figure 1).

Interestingly, even in child-cases labelled malaria, antipyretic administration $(78.8 \%, 65.3-88.9)$ was more fre- quent as first action than administration of antimalarials $(48.1 \%, 34.0-62.4)$. At the same time, the frequency of antimalarial administration was not significantly different between the illness labels or between cases with $(44.7 \%$, 29.9-59.4) or without convulsions (39.4\%, 21.8-57.0). However, herbal medicine was given significantly more often to children with degedege than to children with homa or malaria $(P=0.020)$. For children, there was a significant difference between the areas of residence $(P=0.007)$ with antimalarials being administered most frequently in Ulanga DSS (60\%) and less frequently in Kilombero DSS $(39 \%)$ and Ifakara $(18 \%)$.

In adult cases, administering antipyretics was the most frequent help seeking action for both homa and malaria. Antimalarials were taken more frequently for malaria than for homa $(\mathrm{P}=0.028)$. A cold bath or shower was significantly more frequent in the malaria $(51.4 \%, 34.0-68.6)$ than the homa $(10.5 \%, 1.3-33.1)$ category $(\mathrm{P}=0.003)$. Significantly more adults went to a health facility in Ifakara than in the DSS villages of Kilombero $(P=0.041)$. However, no significant difference between the illness labels was seen in health facility attendance rates.

\section{Sources and appropriateness of malaria treatment}

In order to estimate population coverage with prompt and appropriate malaria treatment ("effective coverage"), key treatment indicators were assessed, including all reported treatment steps (Table 2). An almost 100\% usage of biomedical treatment was noted in adults and children. Antimalarial administration to children was common $(88.8 \%)$ with the majority receiving quinine $(53.8 \%)$. $34.9 \%$ of the children who received quinine, were given an injection or infusion. Less than half of the children and adults received the first-line drug SP. Most of the SP treatments given to children were wrongly dosed. 28.8\% (95\% CI 19.2-40.0) of the children and $12.3 \%(5.1-23.7)$ of the adults were treated with more than one product, most commonly with two $(P=0.022)$.

Few episodes were treated with an antipyretic only, or with an antibiotic. Overall, children (76.3\%) were more often brought to a health facility than adults (56.1\%). Children (53.8\%) were also more likely to receive their antimalarial from a health facility than adults $(29.8 \%)$. Adults rather opted for non-exclusive $(P=0.040)$ or exclusive home-management with antimalarials than children. Generally, drug stores were the most important source for home-treatment, particularly for adults. However, of the 57 children who were brought to a health facility and received an antimalarial, $24.6 \%$ obtained the drugs from a source other than the facility.

Timeliness of treatment with an antimalarial was significantly better in children than in adults. 76.3\% (65.4- 


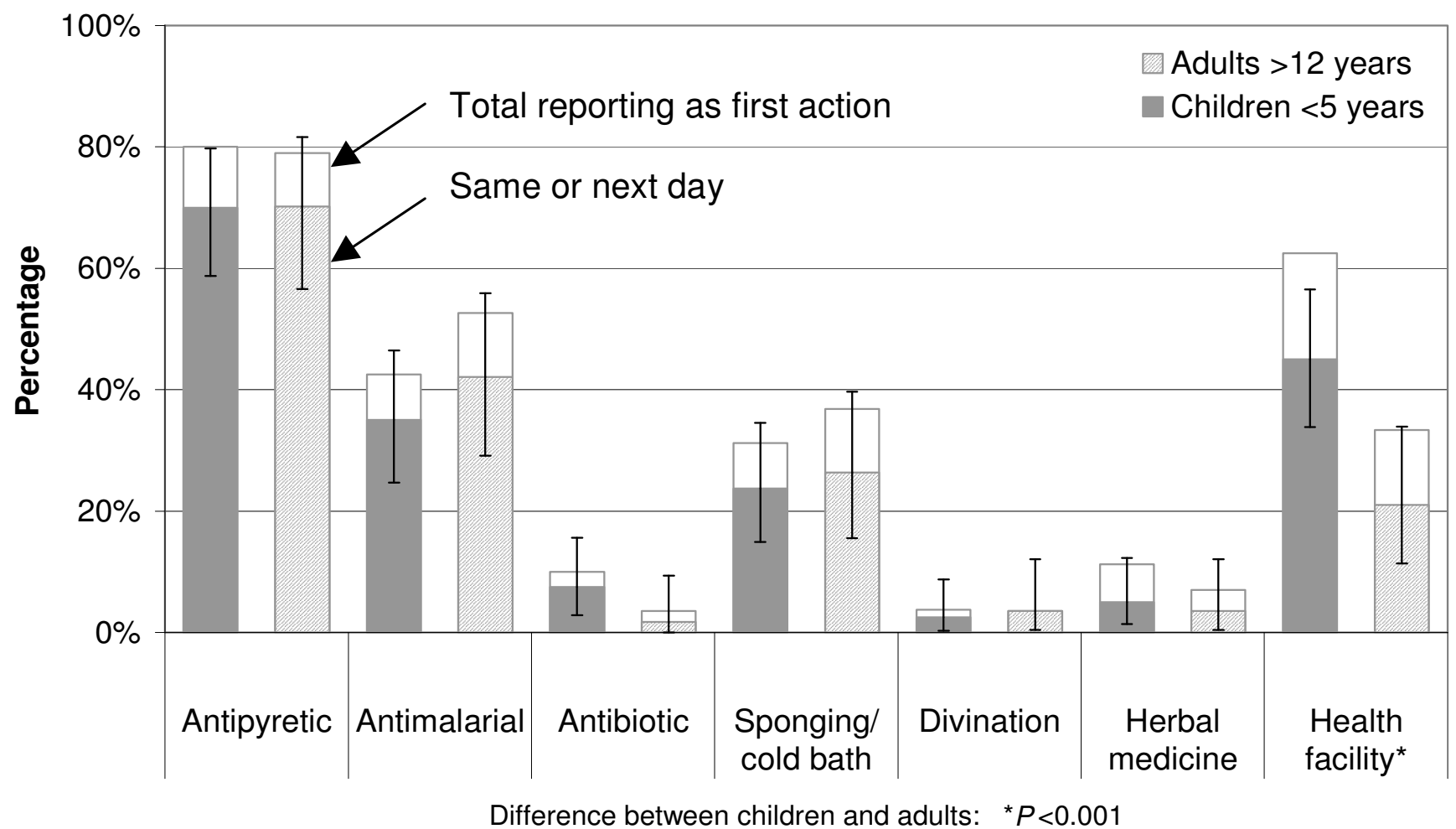

Figure I

Immediate help seeking actions taken on the day of illness onset or the day after. Error bars represent $95 \%$ confidence intervals.

85.1) of the children, but only 56.1\% (42.4-69.3) of the adults received an antimalarial on the day the fever started or the day after $(\mathrm{P}=0.013)$. When adjusted for age group (adults vs. children), those who obtained their antimalarial from a health facility were more likely to receive it on the day the illness started $(P=0.004)$.

\section{Effective community coverage}

Effective community coverage with prompt and appropriate malaria treatment was estimated based on the reported treatment-seeking behaviour for recent fever episodes, taking into account the national treatment guidelines [22]. The main indicators are shown in Figure 2, illustrating how dramatically effective coverage is reduced because of weaknesses in the treatment chain. $87.5 \%$ (78.2-93.8) of the children and 80.7\% (68.1-90.0) of the adults received one of the antimalarials recommended by the national guidelines (SP, amodiaquine or quinine) [22](4) $.72 .5 \%(61.4-81.9)$ of the children and $56.1 \%$ (42.4-69.3) of the adults received these drugs on the day of onset of the symptoms or the day after (5). $42.5 \%$ (31.5-54.1) of the children and 36.8\% (24.4-50.7) of the adults received the antimalarial not only in time, but also in the recommended dose (6). Dosage was assessed based on the patient's or caretaker's accounts. Due to a lack of detailed information, it was assumed that all injections were correctly dosed. Most wrong dosages were underdosages. If also the reported symptoms are taken into account, only $22.5 \%(13.9-33.2)$ of the children and $10.5 \%$ (4.0-21.5) of the adults received timely treatment with an appropriate and correctly dosed antimalarial. SP or amodiaquine was considered appropriate for reported symptoms of uncomplicated malaria, quinine if severe symptoms (incl. difficult breathing, yellow eyes, convulsions, delirium $[22,31])$ had been reported.

\section{Expenditures for antimalarials}

Expenditures for antimalarials of patients exclusively attending either a health facility or a drug store are presented in Table 3. Children and adults paid similar prices in health facilities and in drug stores. Although children should be treated free of charge in public health facilities, they paid on average 540 Tanzanian Shillings (TShs) for antimalarials obtained in health facilities. It was not possible to distinguish between private and public health facilities in this analysis. However, there was no difference between households from villages with either a public or a private health facility, suggesting that exemption mechanisms were not properly implemented. Quinine (median price TShs 570, interquartile range [IQR] 0- 
Table 2: Key indicators for help seeking and access to malaria treatment in individuals with fever in the preceding two weeks

\begin{tabular}{|c|c|c|c|c|c|c|}
\hline \multirow[t]{2}{*}{ Indicator } & \multicolumn{3}{|c|}{$\begin{array}{l}\text { Children } \\
(\mathbf{N}=80)\end{array}$} & \multicolumn{2}{|r|}{$\begin{array}{c}\text { Adults } \\
(\mathbf{N}=57)\end{array}$} & \multirow[t]{2}{*}{$\mathbf{P *}$} \\
\hline & $\mathbf{n}$ & $\%(95 \% \mathrm{Cl})$ & TDHS 2 & $\mathbf{n}$ & $\%(95 \% \mathrm{Cl})$ & \\
\hline Episodes treated & 80 & $100(95.5-100)$ & & 57 & $100(93.7-100)$ & \\
\hline \multicolumn{7}{|l|}{ Medications and dosaging: ${ }^{\prime}$} \\
\hline Modern medicine & 80 & $100(95.5-100)$ & & 56 & $98.3(90.6-100)$ & $0.416^{\infty}$ \\
\hline Antimalarial drug (AM) & 7I & $88.8(79.7-94.7)$ & $58.2(88.6)$ & 47 & $82.5(70.1-91.3)$ & $0.293 \S$ \\
\hline$-S P$ & 38 & $47.5(36.2-59.0)$ & $23.7(33.8)$ & 25 & $43.9(30.7-57.6)$ & $0.673 \S$ \\
\hline - SP correctly dosed & 13 & $16.25(8.9-26.2)$ & & 18 & $31.6(19.9-45.2)$ & $0.035 \S$ \\
\hline - amodiaquine & 10 & $12.5(6.2-21.8)$ & $22.1(29.3)$ & 5 & $8.8(2.9-19.3)$ & $0.49 \mid \S$ \\
\hline - amodiaquine correctly dosed & 5 & $6.3(2.1-14.0)$ & & 3 & $5.3(1.1-14.6)$ & $1.000^{\infty}$ \\
\hline - quinine & 43 & $53.8(42.2-65.0)$ & $11.9(23.5)$ & 23 & $40.4(27.6-54.2)$ & $0.122 \S$ \\
\hline - other AM & 2 & $2.5(0.3-8.7)$ & & I & $\mathrm{I} .8(0.0-9.4)$ & $1.000^{\infty}$ \\
\hline Antipyretic only & 9 & I I.3 (5.3-20.3) & & 9 & $15.8(7.5-27.9)$ & $0.438 \S$ \\
\hline Antibiotic & 8 & $10.0(4.4-18.8)$ & & 2 & $3.5(0.4-12.1)$ & $0.194^{\circ}$ \\
\hline \multicolumn{7}{|l|}{ Treatment sources: ${ }^{1}$} \\
\hline Health facility visit & 61 & $76.3(65.4-85.1)$ & & 32 & $56.1(42.4-69.3)$ & $0.013 \S$ \\
\hline AM from health facility & 43 & $53.8(42.2-65.0)$ & & 17 & $29.8(18.4-43.4)$ & $0.005 \S$ \\
\hline AM not from health facility & 28 & $35.0(24.7-46.5)$ & & 30 & $52.6(39.0-66.0)$ & $0.040 \S$ \\
\hline AM from drug store & 19 & $23.8(15.0-34.6)$ & & 26 & $45.6(32.4-59.3)$ & $0.007 \S$ \\
\hline AM from general shop & 8 & $10.0(4.4-18.8)$ & & 4 & $7.0(2.0-17.0)$ & $0.761^{\infty}$ \\
\hline AM from home stock (or relative/neighbour) & 10 & $\mid 2.5(6.2-2 \mid .8)$ & & 6 & $10.5(4.0-21.5)$ & $0.723 \S$ \\
\hline Exclusive home-management with $\mathrm{AM}^{3}$ & 14 & I $7.5(9.9-27.6)$ & & 18 & $31.6(19.9-45.2)$ & $0.055 \S$ \\
\hline
\end{tabular}

IOne episode may be treated with several drugs from various sources; ${ }^{2}$ Tanzania Demographic and Health Survey $2004-05$ (data for Morogoro Region in brackets); ${ }^{3}$ Episodes never brought to a health facility; $*$ comparison of children and adults; ${ }^{\circ}$ Fisher's exact test; ${ }^{\circledR}$ Chi-square test

1100) was sold frequently and was on average more expensive than SP (TShs 300, IQR 0-500), contributing substantially to total drug expenditures.
Factors related to prompt and effective treatment

Three multivariate logistic models were fitted to assess predictors for the administration of a recommended anti-

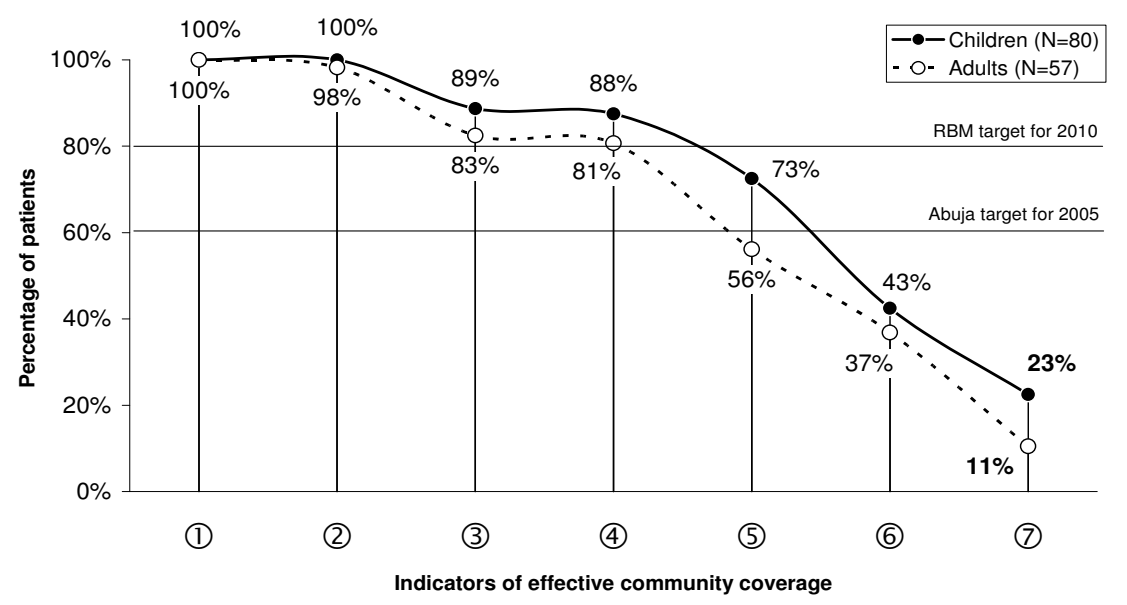

\section{Figure 2}

Estimated effective coverage of fever treatment modelled based on patients' or caretakers' accounts. Percentages are proportions of the study sample with a reported recent fever. (I) Episode treated. (2) Drug administered. (3) Antimalarial administered. (4) Recommended antimalarial. (5) Recommended antimalarial on same or next day. (6) Recommended antimalarial on same/next day, in correct dose. (7) Recommended antimalarial on same/next day, correct dosage, appropriate considering reported symptoms. 
Table 3: Median reported expenditure per one dose of antimalarial treatment in health facilities and drug stores (in TShs). US $\$ 1=$ TShs. I, I 17 (July 2004)*

\begin{tabular}{|c|c|c|c|c|c|c|}
\hline & \multicolumn{3}{|c|}{ Children } & \multicolumn{3}{|c|}{ Adults } \\
\hline & $\mathbf{n}$ & $\begin{array}{c}\text { Median expenditure } \\
\text { (IQR) }\end{array}$ & Range & $\mathbf{n}$ & $\begin{array}{c}\text { Median expenditure } \\
\text { (IQR) }\end{array}$ & Range \\
\hline Health facility & 35 & $540(0-1100)$ & 0 to 3000 & 15 & $500(200-700)$ & 0 to 2700 \\
\hline Drug store & 16 & $600(400-900)$ & 0 to 3600 & 21 & $540(400-800)$ & 60 to 2000 \\
\hline
\end{tabular}

* OANDA currency converter http://www.oanda.com

$\mathrm{IQR}=$ Interquartile range

malarial, as well as for timely and correctly dosed treatment (Figure 3). Models were fitted once for the DSS only and once for both the DSS and Ifakara households. Spatial information and SES were only available for the DSS households.

Fever cases in DSS households were less likely to receive a recommended antimalarial if their illness was labelled homa (fever) $(\mathrm{OR}=0.08)$, they received traditional herbal medicine as first action $(\mathrm{OR}=0.08)$ or they lived in a household with a higher total number of people (OR = $0.79)$. On the other hand, attending a health facility during the course of the illness $(\mathrm{OR}=7.69)$ increased the odds of receiving a recommended antimalarial (Table 4). When this model was fitted with DSS and Ifakara households, only the effects of the homa-label and the number of people in the household were retained. In the univariate analysis, recognising the illness while working in the fields (shamba) and increased distance to the nearest antimalarial provider were also significantly correlated with less antimalarial administration, while reported diarrhoea or vomiting significantly increased the odds. Episodes in DSS households were less likely to receive a recommended antimalarial than those in Ifakara.

The second model assessed predictors for timely treatment (i.e. on the day of illness onset or the day after) among all those receiving a recommended antimalarial. None of the plausible predictors was significantly correlated with the outcome with the exception of a higher number of people in the household, which decreased the odds of timely malarial treatment ( $\mathrm{OR}=0.82,0.69-0.98$ ). The age of the patient, distance to the nearest provider, or prior treatment with other medicines were not found to be significant predictors of the outcome.
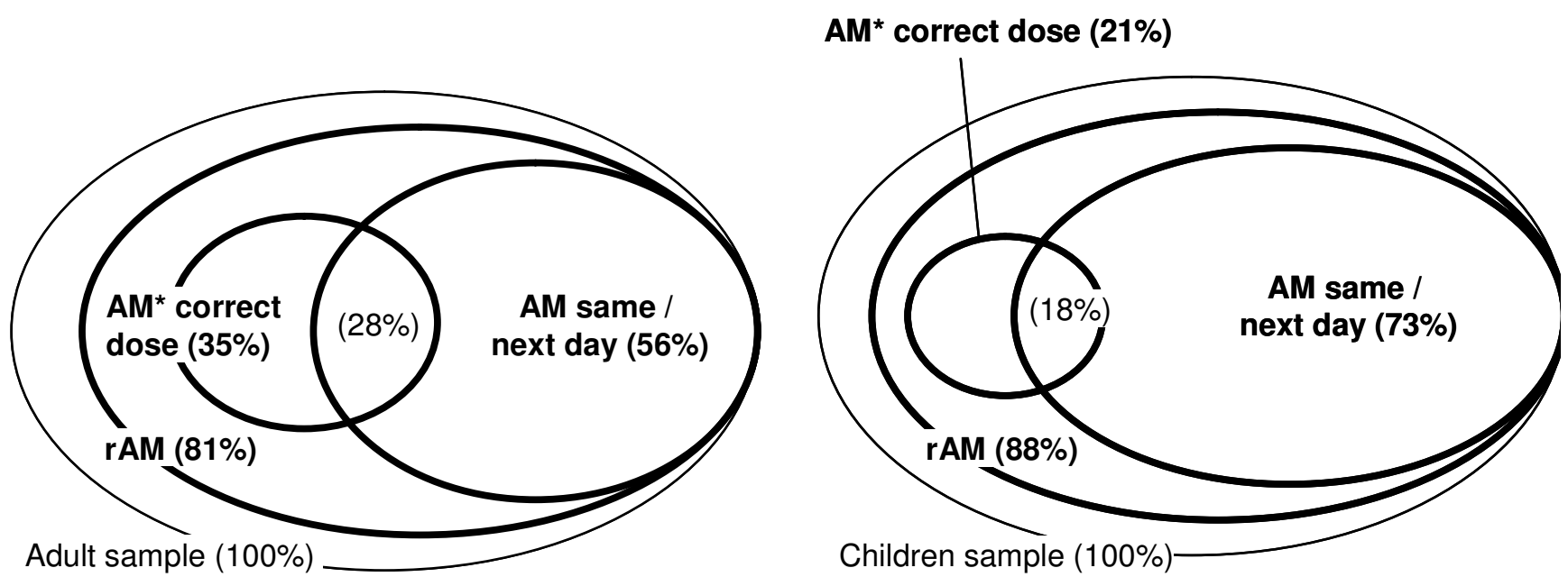

Figure 3

Graphical illustration of treatment indicators assessed in the multivariate models. Circles are roughly proportional to the percentage of patients. $\mathrm{rAM}=$ recommended antimalarial (SP, amodiaquine, quinine). * includes only SP and amodiaquine. 
Table 4: Univariate and multivariate analyses of predictors for administration of a recommended antimalarial (SP, amodiaquine or quinine)

\begin{tabular}{|c|c|c|c|c|c|c|}
\hline \multirow[b]{2}{*}{ Exposure variable } & \multicolumn{3}{|c|}{ Univariate model* } & \multicolumn{3}{|c|}{ Multivariate model*** } \\
\hline & Crude OR & $95 \% \mathrm{Cl}$ & $\mathbf{P}$ & Adjusted OR & $95 \% \mathrm{Cl}$ & $\mathbf{P}$ \\
\hline \multicolumn{7}{|l|}{ Age group } \\
\hline Adult ( $>12$ years) & 1 & & & & & \\
\hline Child ( $<5$ years) & 1.67 & $0.66-4.26$ & 0.280 & & & \\
\hline Total number of people in household & 0.85 & $0.73-0.99$ & 0.041 & 0.79 & $0.64-0.97$ & 0.021 \\
\hline \multicolumn{7}{|l|}{ Place of illness recognition } \\
\hline Home & 1 & & & I & & \\
\hline Shamba & 0.19 & $0.07-0.51$ & 0.001 & 0.29 & $0.08-1.14$ & 0.076 \\
\hline \multicolumn{7}{|l|}{ Diarrhoea or vomiting reported } \\
\hline No & 1 & & & 1 & & \\
\hline Yes & 5.05 & $1.73-14.74$ & 0.003 & 3.24 & $0.85-12.34$ & 0.084 \\
\hline \multicolumn{7}{|l|}{ Signs of severe malaria } \\
\hline \multicolumn{7}{|l|}{ No } \\
\hline Yes & 2.48 & $0.78-7.88$ & 0.125 & 3.60 & $0.73-17.86$ & 0.117 \\
\hline \multicolumn{7}{|l|}{ Illness label (self-defined) } \\
\hline Malaria/degedege & 1 & & & I & & \\
\hline Homa & 0.10 & $0.04-0.29$ & 0.000 & 0.08 & $0.02-0.32$ & $<0.001$ \\
\hline \multicolumn{7}{|l|}{ First action: Antipyretic } \\
\hline No & 1 & & & & & \\
\hline Yes & 0.61 & $0.17-2.23$ & 0.451 & & & \\
\hline \multicolumn{7}{|l|}{ First action: Traditional medicine } \\
\hline No & 1 & & & I & & \\
\hline Yes & 0.24 & $0.07-0.81$ & 0.022 & 0.08 & $0.01-0.48$ & 0.006 \\
\hline \multicolumn{7}{|l|}{ Health facility attendance } \\
\hline No & 1 & & & I & & \\
\hline Yes & 4.46 & $1.69-11.78$ & 0.003 & 7.69 & $1.90-31.11$ & 0.004 \\
\hline \multicolumn{7}{|l|}{ Antimalarial provider in village ${ }^{\prime}$} \\
\hline No & I & & & & & \\
\hline Yes & 2.10 & $0.67-6.59$ & 0.201 & & & \\
\hline Distance to nearest antimalarial provider $(\mathbf{k m})^{* * * / /}$ & 0.01 & $0.00-0.43$ & 0.017 & & & \\
\hline \multicolumn{7}{|l|}{ Study area } \\
\hline Ifakara & 1 & & & & & \\
\hline DSS & 0.22 & $0.05-0.98$ & 0.046 & & & \\
\hline
\end{tabular}

* I37 observations; ** 136 observations; *** 76 observations (DSS only); ' Incl. health facilities, drug stores and general shops stocking antimalarials in mid-2004

The third model assessed predictors for correct dosage among those receiving SP or amodiaquine. This analysis did not consider quinine, as it was not possible to establish the accuracy of the dosage of quinine injections. In this model, children's odds of receiving the correct dose was significantly decreased ( $\mathrm{OR}=0.26,0.09-0.75)$ compared to adults. Cases from DSS households were more likely to receive a correctly dosed drug than those from Ifakara $(\mathrm{OR}=4.44,1.27-15.51)$.

\section{Discussion}

This paper assessed population coverage with prompt and effective malaria treatment from the perspective of those affected. The analysis revealed some important issues for the development of future malaria control strategies. However, in order to establish a comprehensive under- standing of access to health, it may be useful to combine several approaches, as elaborated by Obrist $e t$ al. [6].

Local concepts of malaria will influence successful implementation of effective case-management [32]. This research demonstrated clear changes in the understanding of degedege as compared to historical data. Degedege was traditionally linked to spirits in the form of a bird or a moth and mainly herbal treatment would be administered by traditional healers [29,33]. Studies done between 1995 and 1997 in the same area found that concepts of degedege and malaria were fuzzy; while degedege was sometimes seen as a cause of severe malaria, only mild malaria would be related to mosquito bites $[27,34]$. Today, fevers with convulsions were in most cases labelled malaria rather than degedege. Mosquito bites were usually seen as the cause for convulsions and degedege. These findings are 
currently being validated through an in-depth study on degedege cases. In contrast to degedege, which was considered a severe and dangerous illness [34], homa ("fever") was often regarded as a normal stage in child growth or was attributed to weather conditions. Similar findings have been reported from other regions of Tanzania [28]. While for homa and malaria different symptoms were reported in children, this was not the case in adults. It also appeared that malaria was usually associated with mosquitoes whereas homa was often attributed to other causes. In earlier studies, homa has been described as a label for general malaise and aches, sometimes even in the absence of fever $[35,36]$. To some extent this may explain why fever as a symptom was not most prominent in all homa cases. Nevertheless, local illness labels may still influence treatment-seeking behaviour. As a result, those cases labelled homa were more than 12 times $(\mathrm{OR}=0.08)$ less likely to receive an antimalarial than cases labelled malaria or degedege.

An increasing overlap of the popular and biomedical concepts of malaria can be attributed partly to regular and intensive health education campaigns in the area, from the national "Mtu ni Afya" (Man is Health) campaign in the late 1970s [26] to the intensive social marketing of insecticide-treated nets in the 1990s [27,37]. Nevertheless, factual knowledge does not necessarily translate directly into improved behaviour [34], particularly since appropriate care-seeking depends on several factors other than illness understanding.

In contrast to what has been reported from earlier studies and other areas [38-40], no fever episode remained untreated. Antimalarial administration was common, even for cases with convulsions or labelled degedege and traditional herbal medicine use was rare. This is a major improvement in treatment seeking when compared to a household survey carried out in two DSS villages in 199597, which reported $35 \%$ of degedege episodes were treated with herbal medicine and only $2 \%$ received an antimalarial [26]. It fits well with the findings of de Savigny et al. [41] who reported $78.7 \%$ of sufferers first use biomedical care for cases of fatal malaria in Tanzania. Considering that first treatment with herbal medicine was correlated with less antimalarial use (OR 0.08), discouraging herbal treatment may help to increase treatment rates with antimalarials.

The frequent usage of antipyretics as first treatment may partly reflect a decreased availability of antimalarials in shops [23] and the Tanzanian malaria control policy, which does not actively promote home-based management with antimalarials. Most of the children were brought to a health facility, which increased the chance of receiving a recommended antimalarial. Health facility attendance is generally desirable because other severe febrile illnesses, such as pneumonia or meningitis, can not easily be managed at home. Despite high health facility usage rates, however, the proportion of patients receiving an appropriate antimalarial timely and correctly dosed ( $23 \%$ of all children and $11 \%$ of all adults) was low and too far from the $80 \%$ target set by the RBM Partnership for 2010 [42]. These figures put into perspective the $51.1 \%$ use of a recommended antimalarial on the same or next day for Tanzania and $82.7 \%$ for Morogoro Region reported by the DHS [16]. At the same time, the DHS figures also validate the results of some of our indicators, except for the rates of quinine use, which were extraordinarily high in our study.

Patients, particularly children, who were treated at a health facility, were not more likely to receive an appropriately dosed antimalarial. Reported wrong dosages may be attributed to poor patient adherence or reporting errors. Yet, without any doubt, quality of care is a critical step in assuring appropriate treatment. Merely limiting antimalarial sales to health facilities and drug stores [23] has apparently not resulted in an acceptable quality of case-management. The observed effect of the number of people in a household on (timely) antimalarial treatment may be a chance finding or related to intra-household relations [43]. Yet it may also reflect that in larger families, child care is often delegated from parents to older siblings who may not yet know how to handle an illness episode. In families with more children (or elderly household members), caretakers may be more busy and have less time devote to each one.

Children under 5 years of age should be treated free of charge in (government) health facilities. Yet $25 \%$ of the child episodes seen at a health facility were eventually treated with a shop-bought antimalarial. One might expected that commercial sector treatment of childhood fevers would pose an additional and unnecessary burden on poor households since in the private sector no exemption policy applies. Njau et al. reported significantly higher spending in drug stores (but not general shops) compared to government health facilities [44]. However, data from this study suggests that due to a dysfunctional exemption system drug expenditures did not significantly differ between health facilities and drug stores. In this situation, it may even be cheaper to treat a child with shopbought drugs. A shorter distance to shops than health facilities may result in lower secondary costs for time and transport. This may consequently contribute to higher facility usage rates and possibly to more use of antimalarials by richer households as reported elsewhere [45]. This link, however, could not be proven in our study. 
Stock-outs of SP, amodiaquine, and quinine, which were repeatedly observed in the study area [46], may have forced certain patients to purchase medicines from shops. The commercial sector therefore plays a pivotal role in providing life-saving drugs in the case of delivery-failure of formal health facilities.

The key issues resulting from this research need to be interpreted in consideration of the research methodology and the study setting. Case-selection was based on reported fever rather than lab-confirmed malaria, acknowledging that due to a lack of diagnostics in most primary health facilities episodes of fever suggestive of malaria are treated as such. The Integrated Management of Childhood Illness (IMCI) algorithms (which are implemented in the study area), as well as the national malaria treatment guidelines advocate an assessment and treatment based on clinical signs and symptoms if no microscopy is available [22]. Very often however, a diagnosis is based on the patient's or caretaker's reported symptoms rather than a proper clinical assessment $[47,48]$. The study generally relied on patients' or caretakers' accounts which may result in misreporting of symptoms and treatment seeking behaviour. However, in real life, it is also the patient's perceived ill-health that triggers help-seeking action, rather than a clinical or laboratory diagnosis [4].

When making inferences to other areas one should consider the limited sample size of the studies and the long history of malaria-control and research activities in the study area. The latter would suggest that treatment and coverage rates in the area are likely to be above the Tanzanian average.

It is also worth considering that all estimates presented here did explicitly exclude the aspect of drug efficacy. Yet, actual efficacy of SP in children in nearby Mlimba village was reported to be only $65.7 \%$ (adequate clinical and parasitological response at day 28) [49]. Furthermore, $24 \%$ of SP tablets and $40 \%$ of quinine sulphate tablets collected in the study area did not meet USP specifications for the amount of active ingredient and were mostly under-dosed $[17,50]$. Adding these factors into an effectiveness-model would result in even lower levels of community effectiveness than reported in the coverage figures above.

In the ongoing process of rolling out highly efficacious artemisinin-based combination therapy (ACT), special attention will have to be paid to the quality of prescription in formal health facilities, the ability and willingness of patients to comply with the treatment regimen, as well as to the channels through which these drugs are brought to the patients. It needs to be closely monitored whether restricting ACT to the formal health sector will result in increased community effectiveness (timely administration of correctly dosed efficacious ACT to all those in need) or in a decrease in treatment rates without an improvement in the administered drug regimens.

\section{Conclusion}

In the study area, the local understanding of the biomedical concept of malaria has markedly improved after continuous health education. Further education may have to focus on how, when and where to treat a febrile illness instead of reiterating illness concepts. Availability of antimalarials has been largely limited to certified providers and health facility usage was very popular. Nevertheless, the quality of case-management was far from satisfactory. Decreased drug efficacy and sub-standard drug quality may have further decreased effectiveness at community level. Exemption mechanisms aim to facilitate treatment access for poor and vulnerable groups but in our setting they did not seem to be properly implemented. Private drug retailers played a central role in the provision of timely malaria treatment, complementing the existing formal health services. All these issues can be attributed to a health system which is still too weak to deliver a growing number of increasingly complex health interventions. Such constraints need to be tackled urgently with an increased investment in the local health system in order to translate the high efficacy of newly introduced ACT into equitable community-effectiveness and health-impact.

\section{Competing interests}

The authors declare that they have no competing interests.

\section{Authors' contributions}

MWH was involved in the design and implementation of the studies, analysed and interpreted the data and wrote the manuscript. BO and CL conceived the studies and contributed to the writing, interpretation and discussion of the manuscript. JJM developed the EMIC together with $\mathrm{BO}$ and $\mathrm{MWH}$, and was responsible for its implementation. $\mathrm{RN}$ was in charge of all DSS-related activities. AD contributed to the analysis of the data. AM and CM provided support in the field and contributed to the discussion of the findings. AS and HM contributed to the design of the study and to the discussion of the manuscript.

\section{Additional material}

\section{Additional file 1}

Mean prominence values for patterns of distress (PD) and perceived causes (PC) in children and adults.

Click here for file

[http://www.biomedcentral.com/content/supplementary/14712458-8-317-S1.xls] 


\section{Additional file 2}

Graphical illustration of patterns of distress (PD) and perceived causes (PC) by illness category. Red arrows point out significant differences between the categories. Figure A1: Patterns of distress. Bars represent grouped reported PD. PD with the highest mean prominence values are listed as most prominent PD. Figure A2: Perceived causes. Bars represent grouped PC. PC with the highest mean prominence values are listed as most prominent $P C$.

Click here for file

[http://www.biomedcentral.com/content/supplementary/14712458-8-317-S2.pdf]

\section{Acknowledgements}

Our sincere thanks go to the interviewees in the community and to the field interviewers of the DSS and ACCESS who did the EMIC interviews - asanteni sana! We much appreciated the help and collaboration of community leaders who facilitated our field-work. Special thanks to our research assistant Iddy Mayumana and to Goodluck John who supervised the field-work. Many thanks to the IHRDC data unit and to Hilda Mwabukusi for entering the questionnaires. We greatly appreciate the inputs of Mitchell Weiss on the design and analysis of the EMIC. We thank Tom Smith and Laura Gosoniu for statistical advice and the provision of household GPS and SES data and Sandra Alba for general comments on the manuscript. Many thanks also to Josh Yukich for proof-reading the manuscript. This paper was published with the permission of Dr. Andrew Kitua, Director-General, National Institute for Medical Research. Funding for this research was provided by the Novartis Foundation for Sustainable Development.

\section{References}

I. WHO, UNICEF: World Malaria Report 2005 Geneva: World Health Organization; 2005.

2. World Bank: Key Development Data \& Statistics. 2007 [http:// go.worldbank.org/ISF48T40L0]. 20-7-2007.

3. Committee on the Economics of Antimalarial Drugs: Saving lives, buying time: economics of malaria drugs in an age of resistance Washington, D.C.: National Academies Press; 2004.

4. McCombie SC: Self-treatment for malaria: the evidence and methodological issues. Health Policy Plan 2002, 1 7:333-344.

5. WHO: The world medicines situation. In WHO/EDM/PAR/ 2004.5 Geneva, World Health Organization; 2004.

6. Obrist B, Iteba N, Lengeler C, Makemba A, Mshana C, Mshinda H, Nathan R, Alba S, Dillip A, Hetzel MW, Mayumana I, Schulze A: Exploring and improving access to health care in contexts of livelihood insecurity. Towards a framework for analysis and action. PLoS Med 2007, 4:e308.

7. WHO: The Roll Back Malaria strategy for improving access to treatment through home management of malaria Geneva: World Health Organization (WHO/HTM/MAL/2005.IIOI); 2005.

8. Gyapong M, Garshong B: Lessons learned in Home Management of Malaria: Implementation research in four African countries Geneva: World Health Organization/TDR; 2007.

9. Marsh VM, Mutemi WM, Willetts A, Bayah K, Were S, Ross A, Marsh $\mathrm{K}$ : Improving malaria home treatment by training drug retailers in rural Kenya. Trop Med Int Health 2004, 9:45 I-460.

10. TDR/WHO: Partnership for malaria control: engaging the formal and informal private sectors Geneva: World Health Organization/TDR; 2006.

II. Rowe AK, de Savigny D, Lanata CF, Victora CG: How can we achieve and maintain high-quality performance of health workers in low-resource settings? Lancet 2005, 366:1026-1035.

12. Nyarango P, Gebremeskel T, Mebrahtu G, Mufunda J, Abdulmumini U, Ogbamariam A, Kosia A, Gebremichael A, Gunawardena D, Ghebrat $\mathrm{Y}$, Okbaldet $\mathrm{Y}$ : A steep decline of malaria morbidity and mortality trends in Eritrea between 2000 and 2004: the effect of combination of control methods. Malar J 2006, 5:33.
13. Travis $P$, Bennett $S$, Haines A, Pang T, Bhutta Z, Hyder AA, Pielemeier NR, Mills $A$, Evans T: Overcoming health-systems constraints to achieve the Millennium Development Goals. Lancet 2004, 364:900-906.

14. Singh A: Strengthening health systems to meet MDGs. Health Policy Plan 2006, 2 I:326-328.

15. Feachem RGA, Sabot OJ: Global Malaria Control in the 2 Ist Century: A Historic but Fleeting Opportunity. JAMA 2007, 297:228I-2284.

16. National Bureau of Statistics: Tanzania Demographic and Health Survey 2004-05 Dar es Salaam, Tanzania: National Bureau of Statistics and ORC Macro; 2005

17. Hetzel MW, Iteba N, Makemba A, Mshana C, Lengeler C, Obrist B, Schulze A, Nathan R, Dillip A, Alba S, Mayumana I, Mshinda H: Understanding and improving access to prompt and effective malaria treatment and care in rural Tanzania: the ACCESS Programme. Malar J 2007, 6:83.

18. Armstrong Schellenberg J, Mukasa O, Abdulla S, Marchant T, Lengeler C, Kikumbih N, Mshinda H, Nathan R: Chapter I I. Ifakara DSS, Tanzania. In Population and Health in Developing Countries: Population, Health, and Survival in INDEPTH Sites Volume I. INDEPTH Network. Ottawa: International Development Research Centre; 2002: I59-I64.

19. United Republic of Tanzania. 2002 Population and Housing Census 2003 [http://www.tanzania.go.tz/census/index.html].

20. Drakeley C, Schellenberg D, Kihonda J, Sousa CA, Arez AP, Lopes D, Lines J, Mshinda H, Lengeler C, Armstrong Schellenberg J, Tanner M, Alonso P: An estimation of the entomological inoculation rate for Ifakara: a semi-urban area in a region of intense malaria transmission in Tanzania. Trop Med Int Health 2003, 8:767-74.

21. Killeen GF, Kihonda J, Tami A, Oketch-Okumu FR, Kotas ME, Grundmann H, Kasigudi N, Ngonyani H, Mayagaya V, Nathan R, Abdulla S, Charlwood JD, Smith TA, Lengeler C: Cost-sharing strategies combining targeted public subsidies with private-sector delivery achieve high bednet coverage and reduced malaria transmission in Kilombero Valley, southern Tanzania. BMC Infect Dis 2007, 7:121.

22. MOH: National Guidelines for Malaria Diagnosis and Treatment. United Republic of Tanzania Ministry of Health. Malaria Control Series; 2000.

23. Hetzel MW, Msechu J, Goodman C, Lengeler C, Obrist B, Kachur SP Makemba A, Nathan R, Schulze A, Mshinda H: Decreased availability of antimalarials in the private sector following the policy change from chloroquine to sulphadoxine-pyrimethamine in the Kilombero Valley, Tanzania. Malar J 2006, 5:109.

24. Hetzel MW, Alba S, Fankhauser M, Mayumana I, Lengeler C, Obrist B, Nathan R, Makemba AM, Mshana C, Schulze A, Mshinda H: Malaria risk and access to prevention and treatment in the paddies of the Kilombero Valley, Tanzania. Malar J 2008, 7:7.

25. Weiss MG: Cultural epidemiology: an introduction and overview. Anthropology \& Medicine 2001, 8:5-29.

26. Hausmann Muela S: Community understanding of malaria, and treatmentseeking behaviour, in a holoendemic area of southeastern Tanzania. PhD thesis 2000 [http://pages.unibas.ch/diss/2000/DissB 5427.htm]. University of Basel

27. Minja H, Schellenberg JA, Mukasa $O$, Nathan R, Abdulla S, Mponda $H$, Tanner M, Lengeler C, Obrist B: Introducing insecticide-treated nets in the Kilombero Valley, Tanzania: the relevance of local knowledge and practice for an information, education and communication (IEC) campaign. Trop Med Int Health 200 I, 6:614-23.

28. Mayombana C: Local understanding and practices related to $\mathrm{IMCl}$ interventions in Eastern Tanzania 2004 [http://pages.unibas.ch/diss/2004/ DissB 7I75.htm]. University of Basel

29. Makemba AM, Winch PJ, Makame VM, Mehl GL, Premji Z, Minjas JN, Shiff CJ: Treatment practices for degedege, a locally recognized febrile illness, and implications for strategies to decrease mortality from severe malaria in Bagamoyo District, Tanzania. Trop Med Int Health 1996, I:305-313.

30. Hetzel MW: Access to prompt and effective malaria treatment in the Kilombero Valley, Tanzania 2007 [http://pages.unibas.ch/diss/2007/ DissB 8097.htm]. University of Basel

31. Mackintosh CL, Beeson JG, Marsh K: Clinical features and pathogenesis of severe malaria. Trends Parasitol 2004, 20:597-603.

32. WHO: Implementation of the Global Malaria Control Strategy. Report of a WHO Study Group on the Implementation of the Global Plan of Action for Malaria Control I993-2000. 
In Technical Report Series, No 839 Geneva, World Health Organization; 1993.

33. Oberländer L, Elverdan B: Malaria in the United Republic of Tanzania: cultural considerations and health-seeking behaviour. Bull World Health Organ 2000, 78:1352-1357.

34. Hausmann Muela S, Muela Ribera J, Mushi AK, Tanner M: Medical syncretism with reference to malaria in a Tanzanian community. Soc Sci Med 2002, 55:403-4I 3.

35. Winch PJ, Makemba AM, Kamazima SR, Lurie M, Lwihula GK, Premji Z, Minjas JN, Shiff CJ: Local terminology for febrile illnesses in Bagamoyo District, Tanzania and its impact on the design of a community-based malaria control programme. Soc Sci Med 1996, 42: 1057-1067.

36. Hausmann Muela S, Muela Ribera J, Tanner M: Fake malaria and hidden parasites - The ambiguity of malaria. Anthropology and Medicine 1998, 5:45-61.

37. Armstrong Schellenberg JRM, Abdulla S, Minja H, Nathan R, Mukasa $\mathrm{O}$, Marchant T, Mponda H, Kikumbih N, Lyimo E, Manchester T, Tanner M, Lengeler C: KINET: a social marketing programme of treated nets and net treatment for malaria control in Tanzania, with evaluation of child health and long-term survival. Trans R Soc Trop Med Hyg 1999, 93:225-23I.

38. von Seidlein L, Clarke S, Alexander N, Manneh F, Doherty T, Pinder $M$, Walraven G, Greenwood B: Treatment uptake by individuals infected with Plasmodium falciparum in rural Gambia, West Africa. Bull World Health Organ 2002, 80:790-796.

39. Nsungwa-Sabiiti J, Tomson G, Pariyo G, Ogwal-Okeng J, Peterson S: Community effectiveness of malaria treatment in Uganda a long way to Abuja targets. Ann Trop Paediatr 2005, 25:9I-I00.

40. Amin AA, Marsh V, Noor AM, Ochola SA, Snow RW: The use of formal and informal curative services in the management of paediatric fevers in four districts in Kenya. Trop Med Int Health 2003, 8: II43-II 52.

4I. de Savigny D, Mayombana C, Mwageni E, Masanja H, Minhaj A, Mkilindi Y, Mbuya C, Kasale H, Reid G: Care-seeking patterns for fatal malaria in Tanzania. Malar J 2004, 3:27.

42. RBM Partnership: Global Strategic Plan: Roll Back Malaria 2005 - 2015 Geneva: Roll Back Malaria Partnership; 2005.

43. Molyneux CS, Murira G, Masha J, Snow RW: Intra-household relations and treatment decision-making for childhood illness: a Kenyan case study. J Biosoc Sci 2002, 34: I09-3I.

44. Njau JD, Goodman C, Kachur SP, Palmer N, Khatib RA, Abdulla S, Mills A, Bloland P: Fever treatment and household wealth: the challenge posed for rolling out combination therapy for malaria. Trop Med Int Health 2006, I I:299-3I3.

45. Armstrong Schellenberg J, Victora CG, Mushi A, de Savigny D, Schellenberg $\mathrm{D}$, Mshinda $\mathrm{H}$, Bryce J, the Tanzania IMCI MCE baseline household survey study group: Inequities among the very poor: health care for children in rural southern Tanzania. Lancet 2003, 36I:56I-566.

46. Dillip A, Hetzel MW, Lengeler C, Obrist B, Alba S, Makemba A, Mshana C, Iteba N, Mshinda H: Shortages of Antimalarials in Health Facilities and Shops in Kilombero and Ulanga Districts - Implications for the Roll-Out of Artemisinin-Based Combination Therapy (ACT). Presentation to the 22nd Annual Joint Scientific Conference of the National Institute for Medical Research 2007.

47. Font $F$, Alonso Gonzalez M, Nathan R, Kimario J, Lwilla F, Ascaso C, Tanner M, Menendez C, Alonso PL: Diagnostic accuracy and case management of clinical malaria in the primary health services of a rural area in south-eastern Tanzania. Trop Med Int Health 200I, 6:423-428.

48. Eriksen J, Tomson G, Mujinja P, Warsame MY, Jahn A, Gustafsson LL: Assessing health worker performance in malaria case management of underfives at health facilities in a rural Tanzanian district. Trop Med Int Health 2007, I 2:52-6I.

49. Mugittu K, Abdulla S, Falk N, Masanja H, Felger I, Mshinda H, Beck HP, Genton B: Efficacy of sulfadoxine-pyrimethamine in Tanzania after two years as first-line drug for uncomplicated malaria: assessment protocol and implication for treatment policy strategies. Malar J 2005, 4:55.

50. Braun M: Quality Assessment of Antimalarial Drugs Purchased from Various Sources in Tanzania. Diploma thesis in Pharmaceutical Sciences University of Basel; 2005.

\section{Pre-publication history}

The pre-publication history for this paper can be accessed here:

http://www.biomedcentral.com/1471-2458/8/317/pre pub
Publish with Bio Med Central and every scientist can read your work free of charge

"BioMed Central will be the most significant development for disseminating the results of biomedical research in our lifetime. "

Sir Paul Nurse, Cancer Research UK

Your research papers will be:

- available free of charge to the entire biomedical community

- peer reviewed and published immediately upon acceptance

- cited in PubMed and archived on PubMed Central

- yours - you keep the copyright

Submit your manuscript here:

http://www.biomedcentral.com/info/publishing_adv.asp
BiolMedcentral 